\title{
Bilobed testicle in children: diagnosis and management
}

\author{
Claudio De Carli, MD; ${ }^{*}$ Luis Guerra, MD, MSc; ${ }^{\dagger}$ Michael Leonard, MD, FRCSC, FAAP ${ }^{\ddagger}$
}

\begin{abstract}
Bilobed testicle is an extremely rare testicular malformation in children. It may be presumed that this condition could be an incomplete expression of polyorchidism; however, the etiology of both entities remains unknown. In this report, a 3-year-old boy presented with a right bilobed testicle mimicking a testicular tumour. Since there are insufficient data in the pediatric literature presenting the ideal management of bilobed testicles, we believe it is important to report this case to provide more information about this condition. Although rare, bilobed testis should be considered in the differential diagnosis of a testicular mass. Surgical treatment is not mandatory, and conservative follow-up may play a role.
\end{abstract}

Can Urol Assoc J 2009;3(6):E87-E88

\section{Introduction}

Bilobed testicle is an extremely rare testicular malformation in children. It may be presumed that this condition could be an incomplete expression of polyorchidism; however, the etiology of both entities remains unknown. ${ }^{1}$ To our knowledge, a single patient has been described in the English pediatric literature. ${ }^{2}$ We report the second case and the youngest child, with a bilobed right testicle mimicking a testicular tumour. Since there are insufficient data in the pediatric literature presenting the ideal management in bilobed testicles, we believe it is important to report this case to provide more information about this condition.

\section{Case Report}

A 3-year-old boy presented to our clinic with a 1-year history of right congenital non-communicating hydrocele. Right scrotal examination showed slight enlargement of the right hemiscrotum with positive transillumination, confirming a small hydrocele. Testicular palpation revealed a right painless testicular mass. However, it was difficult to make a distinction between the mass and the normal testicle because of their similar consistency and size. A testicular ultrasound was performed to rule out possible secondary reactive hydrocele associated with testicular tumour. Imaging results showed a bilobed testicular configuration of the right testis measuring $1.9 \times 1.2 \times 1.1 \mathrm{~cm}$ (Fig. 1). The echotexture was similar in both right "hemi-testicular" structures. The epididymis had normal features. The left testis was normal and measured $2.3 \times 1.2 \times 1 \mathrm{~cm}$. A diagnosis of a bilobed right testicle was made. After a 3-year follow-up, which included an annual clinical examination and sonography, we detected no abnormality.

\section{Discussion}

To date, a single case of bilobed testis in a 14-year-old boy has been described. ${ }^{2}$ He was thought to have a testicular mass, and the ultrasound could not rule out tumour of the testis. Surgical exploration was performed and the biopsy confirmed a normal testicle. Since ultrasound technology has improved remarkably, ${ }^{3}$ we consider that surgical exploration is not mandatory as long as the ultrasound appearance is definitive. In our case, testicular ultrasound provided an accurate diagnosis of bilobed testicle and no exploration was required.

Several investigations have attempted to elucidate the mechanism of polyorchidism, ${ }^{4}$ but at present no theory can be confirmed. Currently, the most accepted one is represented by division of the genital ridge by peritoneal bands, in either transverse or longitudinal orientation. It could be postulated that in bilobed testicles, the division of the genital ridge is incomplete, resulting in a bilobed appearance. In our judgment, we consider bilobed testicle a variant of polyorchidism. Besides the potential misdiagnosis of bilobed testis as a testicular tumour, there are 2 other issues that should be discussed. Firstly, the relation between bilobed testicle and testicular torsion, and, secondly, whether the bilobed testicle may develop tumours in the future, such as in polyorchidism.

Clinical management of polyorchidism has been controversial. Some authors have recommended conservative treatment, ${ }^{5,6}$ while others have recommended surgical 


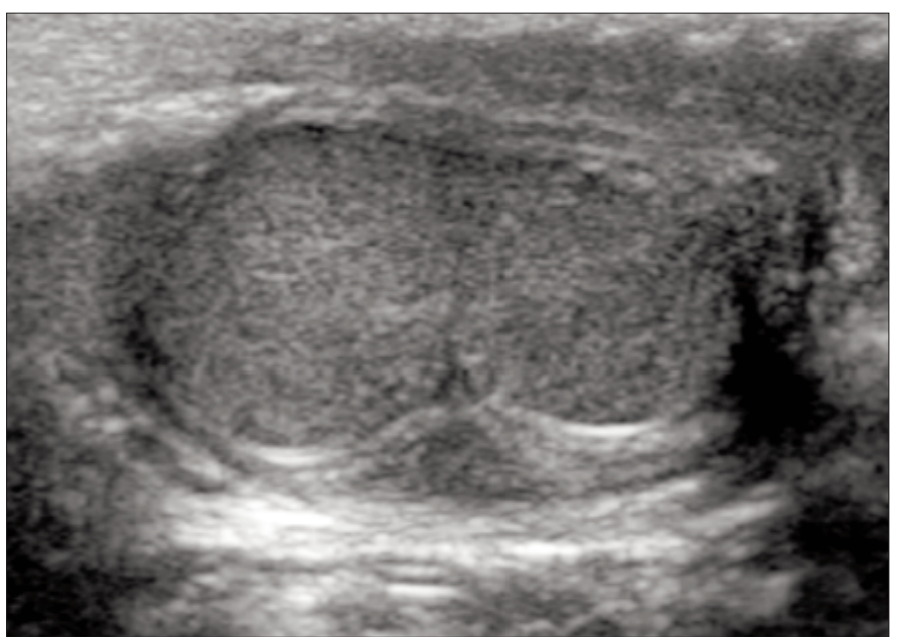

Fig.1. Transverse sonogram demonstrates a bilobed configuration of the right testicle. The right "hemi-testicular" structures have the same normal echogenicity.

management based on the higher prevalence of testicular torsion in polyorchidism when compared with the normal population. ${ }^{7}$ They also advocate that orchiopexy of the contralateral testis is mandatory to avoid possible torsion. Thus, testicular anatomy in polyorchidism may highly predispose to testicular torsion. Furthermore, since we consider bilobed testicles as a variant of polyorchidism, patients and parents should be aware that torsion may occur as a potential complication. To date, after 3 years of follow-up, conservative treatment in our patient has not shown any complication.

It has also been reported that supernumerary testicles can potentially become malignant; ${ }^{7}$ moreover, orchiectomy of the supernumerary testicle is advised in most cases. Controversially, some authors suggest conservative treatment and imaging follow-up with no resection of the supernumerary testis. ${ }^{8}$ For bilobed testicles and malignancy, we believe that as long as both testicular structures demonstrate normal echotexture, conservative treatment and selfexamination are recommended. However, given the distorted anatomy of the gonad, self-examination is more challenging. Consequently, follow-up in clinics is advised and ultrasound imaging should be performed for testicular tumour surveillance.
In addition, polyorchidism has been associated with several pathologies, ${ }^{9}$ such as undescended testes, inguinal hernia and testicular torsion; it is also associated with an increased risk of malignancy. Our case was accompanied with small hydrocele, which is present in $9 \%$ of polyorchidism. ${ }^{3}$

\section{Conclusion}

Bilobed testicles, despite their rarity, should be within the differential diagnosis when a testicular mass is suspected. As bilobed testicle may be a variant of polyorchidism, related potential complications associated with this condition must be considered.

From the ${ }^{\star}$ Clinical Fellow of Division of Pediatric Urology; ${ }^{\dagger}$ Assistant Professor of Surgery (Division of Pediatric Urology) and Clinical Epidemiology; ҒProfessor of Surgery and Pediatrics Chief of Department of Pediatric Urology, Children's Hospital of Eastern Ontario, University of Ottawa, Ottawa, ON

Competing interests: None declared.

This paper has been peer-reviewed.

\section{References}

1. Singer BR, Donaldson JG, Jackson DS. Polyorchidism: functional classification and management strategy. Urology 1992;39:384-8.

2. McAlister WH, Manley CB. Bilobed testicle. Pediatr Radiol 1987;17:82.

3. Ta-Jung C, Wei-Jen Y. Sonographic features of polyorchidism. J Clin Ultrasound 2002;30:106-8.

4. Lazarus BA, Tessler AN. Polyorchidism with normal spermatogenesis. Urology 1974;3:615-6.

5. Thum G. Polyorchidism: a case report and review of literature. J Urol 1991;145:370-2.

6. Khedis M, Nohra J, Dierickx L, et al. Urol Int 2008;80:98-101.

7. Ferro F, lacobelli B. Polyorchidism and torsion. A lesson from 2 cases. J Pediatr Surg 2005;40:1662-4.

8. Berger A, Steiner H, Hoelth L, et al. Ocurrence of polyorchidism in a young man. Urology 2002;60:911.

9. Bhogal RH, Amitabh Prasad KK. Conservative management of polyorchidism in a young man: a case report and review of literature. Pediatr Surg Int 2007;23:689-91.

Correspondence: Dr. Michael Leonard, Department of Pediatric Urology, University of Ottawa, CHEO, 401 Smyth Rd, 0Htawa, 0N K1H 8L1; fax: 613-738-4271; mleonard@cheo.on.ca 